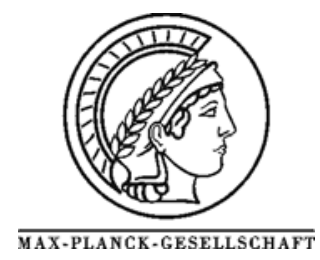

\title{
Catalytically Active States of Ru(0001) Catalyst in CO Oxidation Reaction
}

\author{
R. Blume ${ }^{\dagger}$, M. Hävecker ${ }^{\dagger}$, S. Zafeiratos ${ }^{\dagger}$, D. Teschner ${ }^{\dagger}$, E. Kleimenov ${ }^{\dagger}$, A. Knop-Gericke ${ }^{\dagger *}$, R. Schlögl ${ }^{\dagger}$,

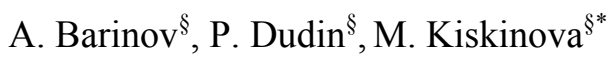 \\ 'Department of Inorganic Chemistry, Fritz-Haber-Institute of the MPG, Faradayweg 4-6, 14195 Berlin, Germany \\ ${ }^{\S}$ Sincrotrone Trieste, AREA Science Park-Basovizza, Trieste-34012, Italy
}

* Corresponding author: e-mail kiskinov@,fhi-berlin.mpg.de or kiskinova@elettra.trieste.it, Phone: +39-0403758549; Fax: +39-040-3758565

Received 24 January 2006, revised 11 February 2006, accepted 15 February 2006, available online 20 March 2006

\begin{abstract}
Identifying the composition of the catalytically active state of metal catalysts under dynamic operating conditions is of particular importance for oxidation catalysis. We report here new insights into the chemical identity of different catalytically active states formed on a Ru(0001) catalyst during the $\mathrm{CO}$ oxidation at different reaction temperatures. The changes in the surface composition of the Ru catalyst and the $\mathrm{CO}_{2}$ yield under varying reaction conditions in the $10^{-4}$ to $10^{-1} \mathrm{mbar}$ pressure range were followed in-situ by synchrotron-based high-pressure $\mathrm{x}$-ray photoelectron spectroscopy and mass spectroscopy. The obtained results reveal that the catalytic activity of a few layers thick 'surface oxide' without well defined stoichiometry and structure is comparable with the activity of the stoichiometric $\mathrm{RuO}_{2}(110)$ phase. The 'surface oxide' forms under reaction conditions when the formation of the $\mathrm{RuO}_{2}$ is kinetically hindered, and can coexist with $\mathrm{RuO}_{2}$ in a wide temperature-pressure range.
\end{abstract}

Keywords: CO oxidation, Ru, high pressure XPS, catalytically active states

\section{Introduction}

Following the pioneering works demonstrating very high activity of the so-called O-rich $\mathrm{Ru}(0001)$ surface in $\mathrm{CO}$ oxidation $[1,2]$, the rutile $\mathrm{RuO}_{2}(110)$, formed on the $\mathrm{Ru}(0001)$ surface under realistic oxidation conditions, is considered as the catalytically active state $[3,4]$. The rutile $\mathrm{RuO}_{2}(110)$ surface consists of alternating rows of six-fold and unsaturated five-fold oxygen coordinated $\mathrm{Ru}$ atoms, the latter, called cus- $\mathrm{Ru}$, playing a prominent role as active sites in $\mathrm{CO}$ oxidation. The inspired UHV surface science and theoretical studies of $\mathrm{CO}$ oxidation reaction on a model $\mathrm{RuO}_{2}(110)$ single crystal surface reached the consensus that the elementary reaction steps involve $\mathrm{CO}$ and $\mathrm{O}$ adsorption on the cus- $\mathrm{Ru}$, followed by reaction between cus- $\mathrm{CO}$ and cus- or bridge $\mathrm{O}$ atoms [5-9]. However, the $\mathrm{RuO}_{2}(110)$ surface is an idealised case of an active Ru catalyst, which has been prompted by the parallel studies focused on the oxidation mechanism of the $\mathrm{Ru}(0001)$ surface and the stability of the $\mathrm{Ru}$ oxidation states at different partial pres- sures and temperatures [10-16]. After the completion of the O-(1x1) adsorption phase [17], the suggested oxidation pathway of the $\mathrm{Ru}(0001)$ surface involves as an important intermediate step the incorporation of $\mathrm{O}$ atoms between the first and second $\mathrm{Ru}$ layers and the formation of an $\mathrm{O}_{\mathrm{ad}}-\mathrm{Ru}$ $\mathrm{O}_{\text {sub }}$ trilayer hosting $2 \mathrm{ML}$ of oxygen $[18,19] 1 \mathrm{ML}$ equals the number of $\mathrm{Ru}$ atoms on the (0001) surface. The conversion into a $\mathrm{RuO}_{2}(110)$ structure is supposed to occur above the critical thickness of two O-Ru-O trilayers (oxygen content of $4 \mathrm{ML}$ ). Spectroscopic evidence for subsurface oxygen species has been provided by photoelectron diffraction and combined photoemission and thermal desorption spectroscopy [20,21] according to another model, based on investigations of $\mathrm{Ru}$ oxidation carried out at $\mathrm{T}>600 \mathrm{~K}$, the $\mathrm{RuO}_{2}$ nucleus is formed as far as the oxygen exceeds $1 \mathrm{ML}$, the coverage of the most dense $(1 \mathrm{x} 1)$ adsorption phase, and the $\mathrm{RuO}_{2}(110)$ film grows progressively in autocatalytic manner $[10,22]$.

The recent XPS microscopy and TDS studies demonstrated that starting from an atomically clean $\mathrm{Ru}(0001)$ 
surface, the formation of a stoichiometric $\mathrm{RuO}_{2}$ phase is kinetically hindered at temperatures lower than $500 \mathrm{~K}$ and readily occurs at higher temperatures [2,13,14,21]. The main reason for such temperature dependence of the $\mathrm{Ru}$ oxidation state is that the incorporation up to $3 \mathrm{ML}$ of oxygen at $\mathrm{T}<500 \mathrm{~K}$ is limited to the top 2-3 Ru layers. These O-rich thin films with poorely-defined $\mathrm{Ru}_{\mathrm{x}} \mathrm{O}_{\mathrm{y}}$ structure are called 'surface oxide' and are identified as the precursor where the $\mathrm{RuO}_{2}$ nucleates and grows at temperatures above $550 \mathrm{~K}$.

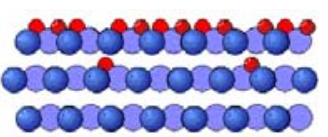

A

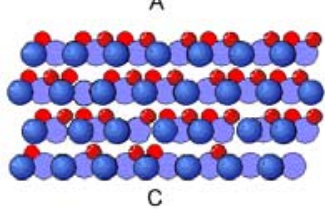

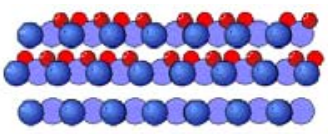

B

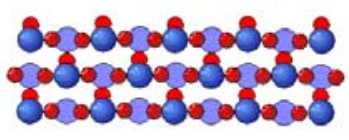

D
Figure 1: Ball models of the oxidation states of $\mathrm{Ru}(0001)$, where $\mathrm{O}$ atoms are the red balls. A: (1x1) saturated oxygen adsorption phase with $\sim 1 \mathrm{ML}$ oxygen, the onset of subsurface $\mathrm{O}$ incorporation at $\mathrm{T} \geq 400 \mathrm{~K}$; $\mathrm{B}$ : 'surface oxide' with $\sim 1 \mathrm{ML}$ incorporated oxygen, the dominant phase formed at $\mathrm{T}<500 \mathrm{~K}$; C: 'surface oxide' with $\geq 2 \mathrm{ML}$ incorporated oxygen; D: rutile $\mathrm{RuO}_{2}(110)$ phase.

Fig. 1 shows schematically the 'oxidation' states of the $\mathrm{Ru}(0001)$ that have attained experimental proof $[2,4,13,14,21]$ In the following we will call them: adsorption phase, referring the state when oxygen in present only on the surface with maximum coverage $1 \mathrm{ML}$ (A), 'surface oxide' with $\sim 1-3 \mathrm{ML}$ oxygen incorporated within the top few $\mathrm{Ru}$ layers (B and C) and rutile $\mathrm{RuO}_{2}$ phase (D). An important finding of XPS microscopy is that 'surface oxide' and $\mathrm{RuO}_{2}$ phases coexist in a wide T-pressure range, even when formed in a pure $\mathrm{O}_{2}$ ambient $[13,21]$ Undoubtedly under reaction conditions, the $\mathrm{CO}$ will drive the oxidation state away from the equilibrium achieved in $\mathrm{O}_{2}$ ambient, which implies that the T-p space of coexistence of the two phases may be expanded.

The temperature dependence of the actual 'oxidation' state and the morphology of the Ru surface reopen the disputable issue about the active state of $\mathrm{Ru}$ catalysts during $\mathrm{CO}$ oxidation. Here, we utilize a specially built reaction chamber for simultaneous monitoring the chemical state of the catalyst surface and the reaction product released in the gas phase at pressures up to a few mbar. We verified the catalytic activity of the different oxidation states of $\mathrm{Ru}(0001)$ catalyst, including the final stoichiometric $\mathrm{RuO}_{2}$, starting from a metallic $\mathrm{Ru}$ surface and following in-situ the temperature evolution of the catalyst surface composition in $\mathrm{CO}+\mathrm{O}_{2}$ environment close to the realistic oxidation, reduction and steady-state reaction conditions.

\section{Experimental}

The experiments were performed in the high pressure XPS station designed and constructed in FHI-MPG [23], attached to the beamline U49/2-PGM2 at the synchrotron radiation facility BESSY in Berlin. The overall energy resolution of the beamline was $0.1 \mathrm{eV}$ at $500 \mathrm{eV}$. The photoelectron spectra were measured in-situ using a set-up combining differential pumping and electrostatic focussing of the emitted photoelectrons [24]. Briefly, the sample was mounted inside the reaction cell, $2 \mathrm{~mm}$ away from an aperture $(1 \mathrm{~mm}$ diameter), which was the entrance of the emitted photoelectrons and reaction products to the differentially pumped stages of the electrostatic lens system of the hemispherical analyser Phoibos 150 (SPECS $\mathrm{GmbH}$ ). The gas phase products, used to measure of the catalytic activity, were monitored on-line by a Hiden mass spectrometer located in the first differentially pumped lens stage. The sample was heated by a laser from the backside. The $\mathrm{CO}$ and $\mathrm{O}_{2}$ gas flows into the reaction cell were regulated by leak valves.

The $\mathrm{Ru}(0001)$ sample was cleaned before each reaction cycle using the well established procedures [14,25]. The base pressure in the chamber was $\sim 2 \times 10^{-8}$ mbar, which reduced the lifetime of the atomically clean surface at room temperature. The temperature ramp used in the present studies was $2 \mathrm{~K}$ per min, and the acquisition of a set of $\mathrm{Ru}$ $3 \mathrm{~d}$ and $\mathrm{O} 1 \mathrm{~s}$ spectra required maximum $4 \mathrm{~min}$. Thus, the maximum difference between the temperature at which the $\mathrm{Ru} 3 \mathrm{~d}$ and $\mathrm{O} 1 \mathrm{~s}$ spectra were taken was less than $8 \mathrm{~K}$. All spectra were normalized to the incident photon flux, monitored by a photodiode with known quantum efficiency. The $\mathrm{Ru} 3 \mathrm{~d}$ and $\mathrm{O} 1 \mathrm{~s}$ spectra were measured with photon energies $450 \mathrm{eV}$ and $650 \mathrm{eV}$, respectively. Using the universal curve for the electron mean free path [26] the effective escape depths for the $\mathrm{O} 1 \mathrm{~s}$ and $\mathrm{Ru} 3 \mathrm{~d}$ photoelectrons is $\sim 5$ $\AA$, which limits the probing depth to the top few layers ( $10 \AA$ ). We also used higher photon energies for increasing the probing depth when necessary.

\section{Results and discussion}

The experiments were carried out at different partial pressure ratios of $\mathrm{CO}$ and $\mathrm{O}_{2}$ in the range between $10^{-4}$ and 0.1 mbar. By varying the $\mathrm{CO} / \mathrm{O}_{2}$ pressure ratio it was possible to reproduce oxidation, reduction and steady-state conditions of the working Ru catalyst. Simultaneous monitoring the dynamic response of the $\mathrm{O} 1 \mathrm{~s}$ and $\mathrm{Ru} 3 \mathrm{~d}_{5 / 2}$ core level spectra and the $\mathrm{CO}_{2}$ production allowed us to correlate the catalytic activity to the actual oxidation state of the $\mathrm{Ru}$ catalyst.

The necessary basis for identification of the adsorption, 'surface oxide' and $\mathrm{RuO}_{2}$ states and verify their actual role in $\mathrm{CO}$ oxidation reaction was provided by the already available $\mathrm{Ru} 3 \mathrm{~d}_{5 / 2}$ and $\mathrm{O} 1$ s core level and TD spectroscopy data. The established binding energies of the $\mathrm{Ru} 3 \mathrm{~d}_{5 / 2}$ and O 1 s components corresponding to the adsorption state, 
'surface oxide' states and rutile $\mathrm{RuO}_{2}$ phase are summarized in Table I.

Table 1: Energy positions of $\mathrm{Ru} 3 \mathrm{~d}_{5 / 2}$ and $\mathrm{O} 1 \mathrm{~s}$ components measured for the different oxidation states. The shift of the $\mathrm{Ru} 3 \mathrm{~d}_{5 / 2}$ components with respect to the zero-energy reference (the position of the $\mathrm{Ru} 3 \mathrm{~d}_{5 / 2}$ bulk component at $280.1 \mathrm{eV}$ ) is given in the brackets.

\begin{tabular}{|c|c|c|c|}
\hline State & $\begin{array}{l}\text { Binding Energy } \\
(\mathrm{eV})\end{array}$ & Component & Ref. \\
\hline \multirow[t]{3}{*}{ Clean $\mathrm{Ru}$} & $280.1(0)$ & $\mathrm{Ru}_{\text {bulk }}$ & 25 \\
\hline & $279.75(-0.35)$ & $\mathrm{Ru}(\mathrm{I})$ & 25 \\
\hline & $280.25(0.15)$ & $\mathrm{Ru}(\mathrm{II})$ & 25 \\
\hline Adsorbed & 280.08 & $\mathrm{Ru}(\mathrm{I})-1 \mathrm{O}_{\mathrm{ad}}$ & 25 \\
\hline \multirow[t]{2}{*}{ phase } & $280.48(0.4)$ & $\mathrm{Ru}(\mathrm{I})-2 \mathrm{O}_{\mathrm{ad}}$ & 4,25 \\
\hline & $281.03(0.93)$ & $\mathrm{Ru}(\mathrm{I})-3 \mathrm{O}_{\mathrm{ad}}$ & 4,25 \\
\hline $\mathrm{RuO}_{2}$ & $280.74(0.64)$ & $\mathrm{RuO}_{2}$-bulk & 4,13 \\
\hline \multirow[t]{2}{*}{ phase } & $280.45(0.35)$ & Ru-cus & 27 \\
\hline & $283(2.92)$ & satellite & \\
\hline 'surface & $280.5 \pm 0.05(\sim 0.4)$ & $\mathrm{Ru}_{\mathrm{x}} \mathrm{O}_{\mathrm{y}}$ & 21 \\
\hline \multirow[t]{4}{*}{ oxide' } & $280.6 \pm 0.05(\sim 0.8)$ & $\mathrm{Ru}(\mathrm{I})-2 \mathrm{O}_{\mathrm{ad}} \mathrm{O}_{\text {sub }}$ & 21 \\
\hline & $281.4 \pm 0.05(\sim 1.3)$ & $\mathrm{Ru}(\mathrm{I})-3 \mathrm{O}_{\mathrm{ad}} \mathrm{O}_{\text {sub }}$ & 21 \\
\hline & $280.9 \pm 0.05(\sim 0.5)$ & $\mathrm{Ru}(\mathrm{II})-\mathrm{O}_{\text {sub }}$ & 21 \\
\hline & 530.0 & $\mathrm{O}_{\mathrm{ad}} \& \mathrm{O}_{\text {sub }}$ & 13 \\
\hline \multirow[t]{2}{*}{$\mathrm{O} 1 \mathrm{~s}$} & 529.5 & $\mathrm{O}$ in $\mathrm{RuO}_{2}$-bulk & 4,13 \\
\hline & 528.7 & 'bridge' O & 4 \\
\hline $\mathrm{O} 1 \mathrm{~s}-\mathrm{CO}$ & $530.8-531.8$ & & 28 \\
\hline
\end{tabular}

The $\mathrm{Ru}(\mathrm{I})$ and $\mathrm{Ru}(\mathrm{II})$ components account for emission from the $\mathrm{Ru}$ atoms in the first and second layer, respectively. They undergo distinct chemical shifts when binding to $\mathrm{O}$, determined by the coordination number of $\mathrm{O}$ atoms and their bonding configuration $[4,25]$. The incorporation of $\mathrm{O}$ subsurface, $\mathrm{O}_{\text {sub }}$, leads to a distinct shift of $\mathrm{Ru}$ (II) resulting in the component $\mathrm{Ru}(\mathrm{II})-\mathrm{O}_{\text {sub }}$ at $\sim 0.5 \mathrm{eV}$, well separated from the $\mathrm{Ru}_{\text {bulk }}$ position [21]. The $\mathrm{Ru}(\mathrm{I})$ energy shift induced by the subsurface oxygen accounts for the $\mathrm{Ru}(\mathrm{I})-2 \mathrm{O}_{\text {ad }} \mathrm{O}_{\text {sub }}$ and $\mathrm{Ru}(\mathrm{I})-3 \mathrm{O}_{\text {ad }} \mathrm{O}_{\text {sub }}$ components at $\sim 0.8$ and $1.3 \mathrm{eV}$, assigned to $\mathrm{Ru}(\mathrm{I})$ atom coordinated with 2 or 3 $\mathrm{O}$ adatoms, respectively, and subsurface oxygen below. When the total amount of adsorbed and incorporated oxygen exceeds $\sim 3 \mathrm{ML}$ a new broad component at $\sim 0.4 \mathrm{eV}$, $\mathrm{Ru}_{\mathrm{x}} \mathrm{O}_{\mathrm{y}}$, grows. It corresponds to the most advanced oxidation state below $500 \mathrm{~K}$ with a poorly-defined structure and thickness of about two rutile layers (5-6 $⿱$ ) [21]. Although the energy position of the $\mathrm{Ru}_{\mathrm{x}} \mathrm{O}_{\mathrm{y}}$ component is practically identical with the $\mathrm{Ru}(\mathrm{I})-2 \mathrm{O}_{\mathrm{ad}}$ one, the $\mathrm{Ru} 3 \mathrm{~d}$ spectra are very different, because of the strong attenuation of $\mathrm{Ru}_{\text {bulk }}$ component due to screening by the 'surface oxide' film. The $\mathrm{RuO}_{2}(110)$ phase has two components corresponding to the cus- $\mathrm{Ru}$ and six-fold coordinated $\mathrm{Ru}$ atoms and a broad satellite at $\approx 283 \mathrm{eV}[4,13,27]$. The $\mathrm{O} 1 \mathrm{~s}$ spectra from the adsorption and 'surface oxide' states appear at 530.0 $\mathrm{eV}$, the latter being only a bit broader, indicative of multiple bonding configurations [13]. The $\mathrm{O} 1 \mathrm{~s}$ spectrum of the $\mathrm{RuO}_{2}(110)$ phase has two components, reflecting the emission from the bridge-O atoms at the $\mathrm{RuO}_{2}$ surface (528.7 eV) and bulk $\mathrm{RuO}_{2}$ oxygen $(529.5 \mathrm{eV})[4,13]$. The 'bridge' oxygen component is well visible only when the $\mathrm{RuO}_{2}(110)$ surface is very well ordered and without oxygen vacancies. Since the 'bridge' oxygen participates in the oxidation reactions $[9,10]$ the corresponding $\mathrm{O}$ 1s component should be strongly reduced in $\mathrm{CO}$ ambient.

For the presence of adsorbed $\mathrm{CO}$ we judged from the $\mathrm{O}$ 1s spectra, because the $\mathrm{C} 1 \mathrm{~s}$ peak overlaps with the $\mathrm{Ru}$ $3 \mathrm{~d}_{3 / 2}$ core level. The $\mathrm{O} 1 \mathrm{~s}$ peaks of $\mathrm{CO}$ have binding energies between 530.8 and $531.8 \mathrm{eV}$ and can be easily resolved from those of adsorbed oxygen and oxide [28].

\subsection{Reduction of the 'surface oxide' and $\mathrm{RuO}_{2}$}

The 'surface oxide' (Fig. 2) and stoichiometric $\mathrm{RuO}_{2}$ phase (Fig. 3) were formed by exposing $\mathrm{Ru}(0001)$ to $5 \times 10^{-2}$ mbar $\mathrm{O}_{2}$ at $450 \mathrm{~K}$ and $620 \mathrm{~K}$, respectively. The 'surface oxide' contained $\sim 1.5-2.0$ ML oxygen located on the surface and between the top and second $\mathrm{Ru}$ layer. The experiments were carried out in the $10^{-4}$ mbar range at $\mathrm{CO} / \mathrm{O}_{2}$ partial pressure ratio of 4 , i.e. in excess of $\mathrm{CO}$. The reduction rate was compatible with simultaneous monitoring of the XPS and mass spectra, while slowly increasing the sample temperature, starting from $370 \mathrm{~K}$. The results provide the necessary basis for understanding and interpretation the in-situ $\mathrm{CO}$ oxidation data.

Figure 2(a) shows representative $\mathrm{Ru} 3 \mathrm{~d}_{5 / 2}$ spectra obtained during reduction of 'surface oxide'. The bottom $\mathrm{Ru}$ $3 \mathrm{~d}_{5 / 2}$ spectrum is of a 'clean' Ru surface, before exposure to $1 \times 10^{-2} \mathrm{mbar}_{2}$ at $450 \mathrm{~K}$. Although some $\mathrm{CO}$ from residual gas adsorbs on the surface at $2 \times 10^{-8}$ mbar base pressure, its coverage is relatively low at $450 \mathrm{~K}$ and the surface component $\mathrm{Ru}(\mathrm{I})$ is still present. For deconvolution we used a broader component to account for the bulk and Ru(II) contributions. The $\mathrm{Ru} 3 \mathrm{~d}_{5 / 2}$ spectrum of the 'surface oxide' before the reaction contains components at $\sim 0.5 \mathrm{eV}, 0.8 \mathrm{eV}$ and at $1.3 \mathrm{eV}$, which appear only in the presence of about 1 ML incorporated oxygen [21]. Our previous XPS microscopy results did not show significant lateral inhomogeneity for such low temperature oxidation states [21]. The broad $\mathrm{O}$ $1 \mathrm{~s}$ spectrum in the bottom Fig. 2(b), peaked at $530.0 \mathrm{eV}$, corresponds to the 'surface oxide'.

The onset of reduction was at $\sim 390 \mathrm{~K}$ with a maximum $\mathrm{CO}_{2}$ yield at $\sim 420 \mathrm{~K}$, followed by a fast decay to zero at $\sim 450-470 \mathrm{~K}$. It leads to a decrease of the $\mathrm{O} 1 \mathrm{~s}$ signal (Fig. 2(c)) and significant changes in the $\mathrm{Ru} 3 \mathrm{~d}_{5 / 2}$ spectrum: the $\mathrm{Ru}_{\text {bulk }}$ grows, accompanied by fast attenuation of 
the $\mathrm{Ru}(\mathrm{I})-2 \mathrm{O}_{\mathrm{ad}} \mathrm{O}_{\text {sub }}$ at $0.8 \mathrm{eV}$, whereas the $\mathrm{Ru}(\mathrm{II})-\mathrm{O}_{\text {sub }}$ at 0.5 $\mathrm{eV}$ broadens and gradually shifts to $0.4 \mathrm{eV}$, the position of the $\mathrm{Ru}(\mathrm{I})-2 \mathrm{O}_{\mathrm{ad}}$ component. The results indicate that once the oxygen from the surface is consumed, the limited amount of oxygen incorporated between the first and second layer is thermodynamically driven to segregate to the surface [18]. Thus the system converts into an oxygen adsorption phase. A peculiar feature in the evolution of the $\mathrm{Ru} 3 \mathrm{~d}_{5 / 2}$ spectra is that the $\mathrm{Ru}(\mathrm{I})-3 \mathrm{O}_{\mathrm{ad}}$ component at $0.9 \mathrm{eV}$ does not gain sensible intensity, which indicates direct reduction of the 'surface oxide' into an adsorption state with moderate oxygen coverage of $\sim 0.7 \mathrm{ML}$.
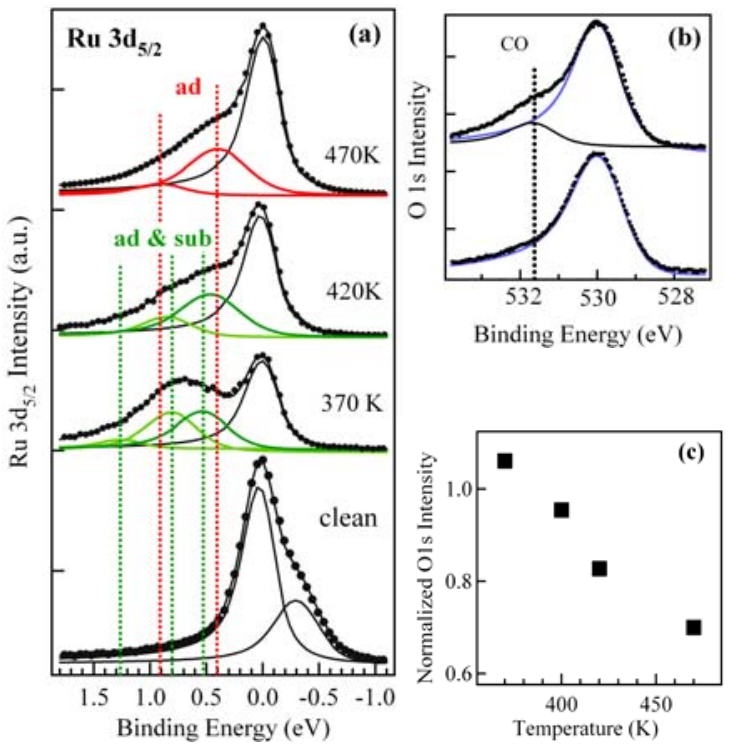

Figure 2: (a) From bottom to top: $\mathrm{Ru} 3 \mathrm{~d}_{5 / 2}$ spectra taken before exposure to $\mathrm{O}_{2}$, after oxidation at $450 \mathrm{~K}$ and cooling the 'surface oxide' to $370 \mathrm{~K}$ and following reduction with increasing the temperature. The 'ad \& sub' annotation indicates the three components, $\mathrm{Ru}(\mathrm{I})-3 \mathrm{O}_{\mathrm{ad}} \mathrm{O}_{\text {sub }} \mathrm{Ru}(\mathrm{I})-2 \mathrm{O}_{\mathrm{ad}} \mathrm{O}_{\text {sub }}$ and $\mathrm{Ru}(\mathrm{II})-\mathrm{O}_{\text {sub }}$, which are fingerprints of the O-rich state with incorporated oxygen. (b) O 1s spectra taken after oxidation at $450 \mathrm{~K}$ (bottom) and after exposure of this surface to $\mathrm{CO}$ at $320 \mathrm{~K}$ (top). (c) $\mathrm{O} 1 \mathrm{~s}$ intensity as a function of reduction temperature. The $\mathrm{O} 1 \mathrm{~s}$ signal is normalised assuming that the intensity of the adsorption phase corresponds to $0.7 \mathrm{ML}$. $\mathrm{dT} / \mathrm{dt}=2 \mathrm{deg} / \mathrm{min}$. Reduction conditions: $\mathrm{P}_{\mathrm{CO}}=2 \times 10^{-4} \mathrm{mbar}, \mathrm{P}_{\mathrm{O} 2}=0.5 \times 10^{-4} \mathrm{mbar}$.

Simple calculations, considering the electron escape depth for our experimental set-up, will predict that for 'surface oxide' with initial load of 2 ML the reduction to 0.7 ML adsorption phase should cause a decrease of the $\mathrm{O} 1 \mathrm{~s}$ intensity by $\sim 50 \%$ ( $1 \mathrm{ML}$ subsurface oxygen contributes to $\sim 30 \%$ of the initial signal). The experimentally measured decrease of the $\mathrm{O} 1 \mathrm{~s}$ intensity by about $35 \%$ is indicative that the total initial load of oxygen within the top two Ru layers is somewhat less than $2 \mathrm{ML}$. In fact, the $\mathrm{Ru}(\mathrm{I})$ $3 \mathrm{O}_{\text {ad }} \mathrm{O}_{\text {sub }}$ component at $\sim 1.3 \mathrm{eV}$ is already rather weak in the $\mathrm{Ru} 3 \mathrm{~d}_{5 / 2}$ spectra from the 'surface oxide' before the reduction, compatible with the presence of vacancies on the surface. This also is consistent with the evolution of the Ru $3 \mathrm{~d}_{5 / 2}$ spectra during the reduction, which does not pass through a saturated adsorption layer of $1 \mathrm{ML}$. One possible explanation is that once the oxygen starts to incorporate below the surface it naturally leaves vacancies on the surface $[18,29]$, where $\mathrm{CO}$ can stick and react. Indeed, when the freshly formed 'surface oxide was cooled to $370 \mathrm{~K}$ and exposed to $\mathrm{CO}$ ambient a shoulder at about $531.7 \mathrm{eV}$ grows in the $\mathrm{O} 1 \mathrm{~s}$ spectrum due to adsorption of $\mathrm{CO}$ molecules (Fig. 2(b)). By varying the $\mathrm{CO} / \mathrm{O}$ pressure ratio the initial 'surface oxide' can be restored under oxidizing conditions at $450 \mathrm{~K}$, whereas under reducing conditions the adsorbed $\mathrm{O}$ can be further depleted only at temperatures above 600 $\mathrm{K}$, which leaves a diluted adsorption state with mostly single coordinated $\mathrm{Ru}$ atoms.

The $\mathrm{Ru} 3 \mathrm{~d}_{5 / 2}$ spectrum after oxidation in $10^{-2} \mathrm{mbar}$ $\mathrm{O}_{2}$ at $620 \mathrm{~K}$ (Fig. 3(a)) did not contain a $\mathrm{Ru}_{\text {bulk }}$ component, even when measured using photon energies of $1000 \mathrm{eV}$, which increased the probing depth. This indicates that the formed stoichiometric $\mathrm{RuO}_{2}$ film is thicker than $\sim 15 \AA$. The bulk oxide component dominates the spectra but also the Ru-cus component is present, which suggests an uniform and structured $\mathrm{RuO}_{2}(110)$ surface. The $\mathrm{O}$ 1s spectrum in Fig. 3(b) is peaked at $529.5 \mathrm{eV}$, as expected for the $\mathrm{RuO}_{2}$ phase, with broadening on the side of the O-bridge surface component at $528.7 \mathrm{eV}[4,13]$.

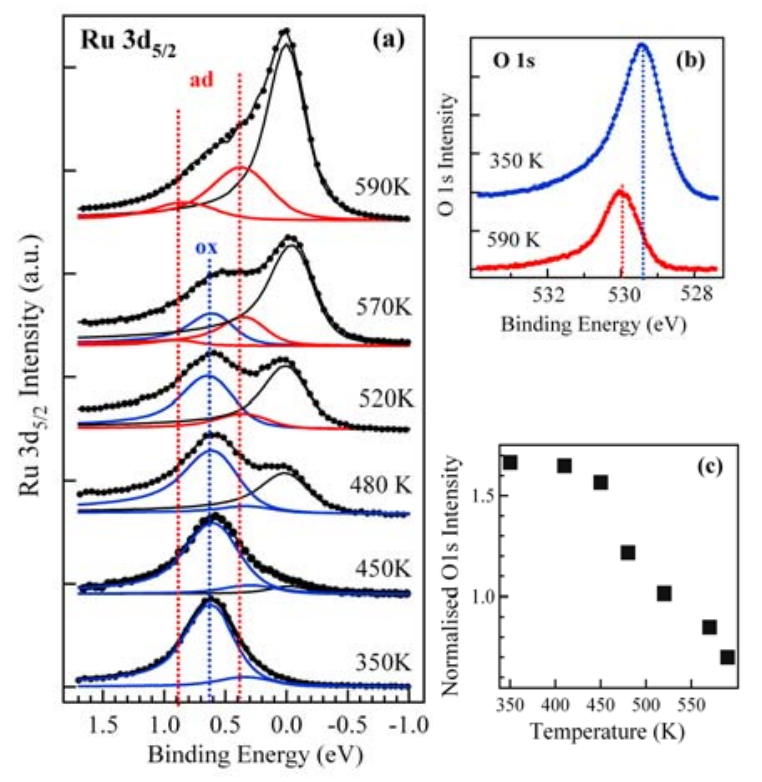

Figure 3: (a) From bottom to top: $\mathrm{Ru} 3 \mathrm{~d}_{5 / 2}$ spectra taken after oxidation at $620 \mathrm{~K}$ and cooling to $350 \mathrm{~K}$, and following reduction with increasing the temperature. (b) $\mathrm{O} 1 \mathrm{~s}$ spectra taken before introducing $\mathrm{CO}$ (top) and after reduction to adsorption phase (bottom) (c) $\mathrm{O} 1$ s intensity changes with increasing the reduction temperature. The $\mathrm{O} 1 \mathrm{~s}$ signal is normalised against the intensity of the adsorption phase, corresponding to $0.7 \mathrm{ML}$. $\mathrm{dT} / \mathrm{dt}=2 \mathrm{~K} / \mathrm{min}$. Reduction conditions: $\mathrm{P}_{\mathrm{CO}}=2 \times 10^{-4}$ mbar, $\mathrm{P}_{\mathrm{O} 2}=0.5 \times 10^{-4}$ mbar. 

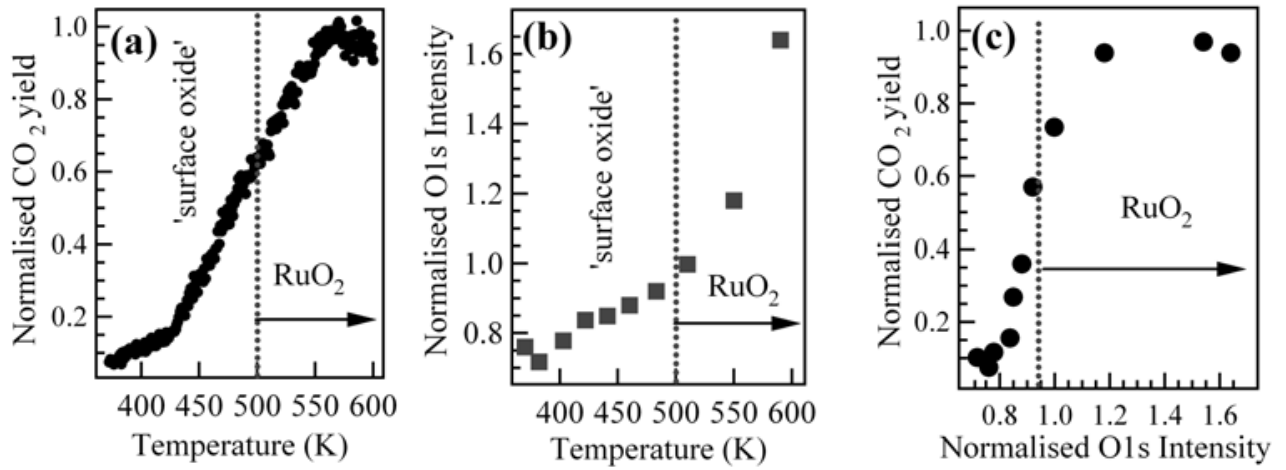

Figure 4: (a) $\mathrm{CO}_{2}$ yield as a function of reaction temperature; (b) $\mathrm{O} 1 \mathrm{~s}$ intensity after subtraction of the $\mathrm{CO}$ contribution as a function of reaction temperature. The $\mathrm{O} 1 \mathrm{~s}$ signal is normalised as in the reduction experiments (see Figs. 3(b) and 2(b)). The $\mathrm{O}$ $1 \mathrm{~s}$ intensity up to $\sim 500 \mathrm{~K}$ reflects only the surface and subsurface content, whereas above $500 \mathrm{~K}$ the increase is dominated by the formation of an $\mathrm{RuO}_{2}$ phase. (c) Plot of the $\mathrm{CO}_{2}$ yield versus $\mathrm{O}$ content at the surface and near surface region. The dashed line in (a) - (c) indicates the onset of the $\mathrm{RuO}_{2}$ growth.

The $\mathrm{CO}_{2}$ formation starts at $\sim 420 \mathrm{~K}$ and is clearly marked by the appearance and growth of the $\mathrm{Ru}_{\text {bulk }}$ compo nent with increasing reaction temperature and decrease of the $\mathrm{O}$ 1s intensity. As illustrated by the plot in Fig. 3(c), the most rapid loss of $\mathrm{O} 1 \mathrm{~s}$ intensity occurs at $\sim 450-470 \mathrm{~K}$, when the maximum $\mathrm{CO}_{2}$ yield was monitored. The evolution of the $\mathrm{Ru} 3 \mathrm{~d}_{5 / 2}$ spectra in Fig. 3(a) illustrates how the on-going reaction continuously consumes the oxide. Above $\sim 520 \mathrm{~K}$ the $\mathrm{Ru}(\mathrm{I})-2 \mathrm{O}_{\mathrm{ad}}$ component starts to grow as well, accompanied by an accelerated increase of the $\mathrm{Ru}_{\text {bulk }}$ and attenuation of the oxide component. This indicates a patchy morphology of the surface, consisting of diminishing oxide islands and inactive adsorption phase. Above $\sim 580 \mathrm{~K}$ the $\mathrm{Ru} 3 \mathrm{~d}_{5 / 2}$ spectrum becomes almost identical to that of the inactive adsorption state with $\sim 0.7 \mathrm{ML}$ of oxygen, achieved during reduction of the 'surface oxide' (see Fig. 2(a)). The apparent direct conversion from $\mathrm{RuO}_{2}$ to an inactive adsorption phase is supported by the evolution of the $\mathrm{RuO}_{2}$ satellite (not shown), distinguishable in the $\mathrm{Ru} 3 \mathrm{~d}$ spectra up to $550 \mathrm{~K}$. This is consistent with the results in Fig. 2, which show that the 'surface oxide' is unstable at $\mathrm{T}>500 \mathrm{~K}$ under reduction conditions, and the shift of the $\mathrm{O} 1 \mathrm{~s}$ spectrum in Fig. 3(b) to $530.0 \mathrm{eV}$.

In brief, the stabilities of the 'surface oxide' and the stoichiometric $\mathrm{RuO}_{2}$ under reduction condition appear comparable; both can be easily reduced in excess of $\mathrm{CO}$ in the gas phase mixture at $\mathrm{T}>400 \mathrm{~K}$ and the final reduced state at $\mathrm{T}<600 \mathrm{~K}$ is the same inactive adsorption phase with $\sim 0.7 \mathrm{ML}$ of oxygen. It should be noted that in surface science experiments, carried out at temperature and pressure conditions far from the realistic ones, no reduction of the $\mathrm{RuO}_{2}(110)$ was observed even in extreme excess of $\mathrm{CO}$, i.e. $\mathrm{CO}: \mathrm{O}_{2}$ pressure ratios of 10 [7].

\subsection{Catalytically active transient states of $R u$ surface during $\mathrm{CO}$ oxidation at different tem- peratures}

The experiments were carried out at $0.1 \mathrm{mbar}$ with $\mathrm{CO}: \mathrm{O}_{2}$ partial pressure ratio 1 . We started from a clean $\mathrm{Ru}(0001)$ surface slowly increasing the temperature after introduction of the reactants in the gas phase. The excess of oxygen with respect to the reaction stoichiometry provided slightly oxidizing conditions in order to ensure the formation of stoichiometric $\mathrm{RuO}_{2}$ above $500 \mathrm{~K}$, which did not readily occur using the stoichiometric $\mathrm{CO}: \mathrm{O}_{2}$ ratio of 2 . Another reason for choosing this $\mathrm{CO}: \mathrm{O}_{2}$ ratio is that the highest turnover rates over working $\mathrm{Ru}$ catalysts under realistic conditions were measured at about equal partial pressures of the reactants [30].

The mass spectrometry and XPS data allowed us to correlate the $\mathrm{CO}_{2}$ yield and the oxidation state of the catalyst at different reaction temperature, ranging from 370 to $600 \mathrm{~K}$. Figure 4(a) shows the evolution of the $\mathrm{CO}_{2}$ yield with increasing reaction temperature. The plot has three distinct regions: a very weak increase up to $\sim 420 \mathrm{~K}$, a sharp onset of the oxidation reaction at $\sim 420 \mathrm{~K}$ with the $\mathrm{CO}_{2}$ yield continuously increasing up to $\sim 550 \mathrm{~K}$, followed by a flat maximum and slow decline above $\sim 580 \mathrm{~K}$.

The evolution of the $\mathrm{Ru}$ oxidation state with increasing reaction temperature is illustrated by the selected $\mathrm{O} 1 \mathrm{~s}$ and $\mathrm{Ru} 3 \mathrm{~d}_{5 / 2}$ spectra in Fig. $5(\mathrm{a}, \mathrm{b})$. The surface composition of $\mathrm{Ru}$ catalyst in the $\mathrm{CO}+\mathrm{O}_{2}$ ambient at temperatures before the sharp onset of the $\mathrm{CO}_{2}$ production is best represented by the $\mathrm{O} 1 \mathrm{~s}$ spectra in Fig. 5(a), taken at $\mathrm{T}<420 \mathrm{~K}$. They clearly show the presence of $\mathrm{CO}$ on the surface (component at $\sim 531.7 \mathrm{eV}$ ) up to temperatures $\sim 400 \mathrm{~K}$. The CO removal in the temperature range $400-420 \mathrm{~K}$ is accompanied by some loss of the $\mathrm{O} 1 \mathrm{~s}$ intensity at $530.0 \mathrm{eV}$, assigned to surface and subsurface oxygen, and by a weak 
increase of the $\mathrm{CO}_{2}$ yield. This suggests that the adsorbed $\mathrm{CO}$ reacts with surface $\mathrm{O}$ and leaves the surface as $\mathrm{CO}_{2}$.
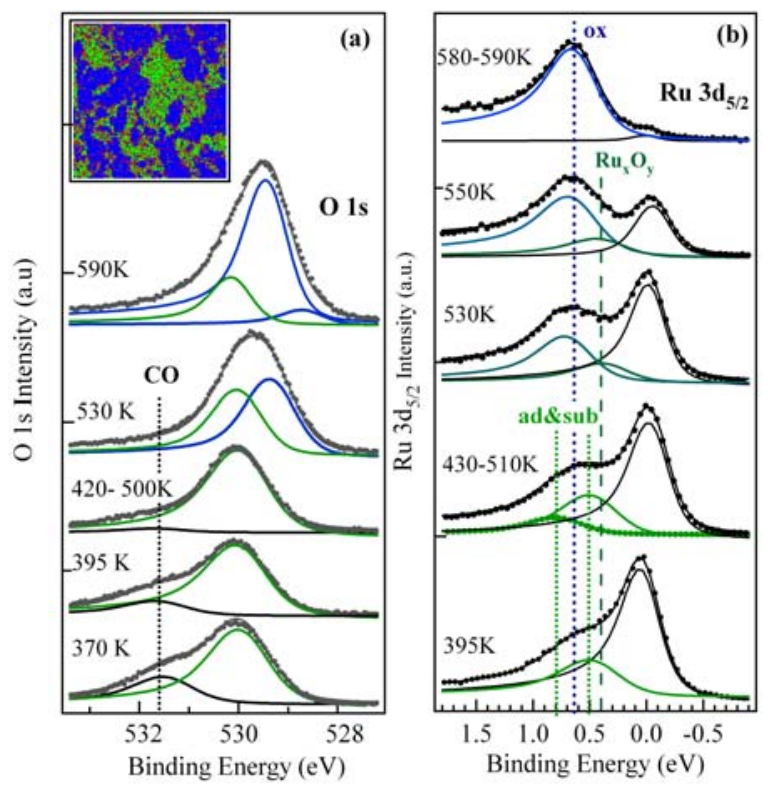

Figure 5: $\mathrm{O} 1 \mathrm{~s}$ (a) and $\mathrm{Ru} 3 \mathrm{~d}_{5 / 2}$ (b) spectra illustrating the catalyst composition developed during $\mathrm{CO}$ oxidation with increasing of the reaction temperature from 370 to $600 \mathrm{~K}$. $\mathrm{dT} / \mathrm{dt}=2 \mathrm{~K} / \mathrm{min}$. Reaction conditions: $\mathrm{P}_{\mathrm{CO}}=0.5 \times 10^{-1} \mathrm{mbar}$, $\mathrm{P}_{\mathrm{O} 2}=0.5 \times 10^{-1}$ mbar. The insert in (a) is a $\mathrm{Ru} 3 \mathrm{~d}$ map illustrating the surface morphology developed after exposure to $10^{6} \mathrm{~L} \mathrm{O}_{2}$ at $670 \mathrm{~K}$ with $\mathrm{RuO}_{2}$ (blue) and $\mathrm{Ru}_{\mathrm{x}} \mathrm{O}_{\mathrm{y}}$ (green) islands [31]

This scenario is in accordance with the $\mathrm{Ru} 3 \mathrm{~d}_{5 / 2}$ spectrum in Fig. 5(b) taken at $395 \mathrm{~K}$, where the absence of $\mathrm{Ru}(\mathrm{I})$ $2 \mathrm{O}_{\mathrm{ad}} \mathrm{O}_{\text {sub }}$ component indicates that the $\mathrm{O}$ surface coverage is substantially reduced after the removal of $\mathrm{CO}$. We did not consider here the $\mathrm{Ru} 3 \mathrm{~d}_{5 / 2}$ spectrum before the removal of $\mathrm{CO}$, because of the unknown effect of the $\mathrm{CO}$ on the surface core level position. The $\mathrm{O} 1 \mathrm{~s}$ peak at $530.0 \mathrm{eV}$ gains intensity above $400 \mathrm{~K}$ indicating further accumulation of oxygen, which also leads to the increase of $\mathrm{Ru}(\mathrm{II})$ $\mathrm{O}_{\text {sub }}$ and $\mathrm{Ru}(\mathrm{I})-2 \mathrm{O}_{\mathrm{ad}} \mathrm{O}_{\text {sub }}$ components in the $\mathrm{Ru} 3 \mathrm{~d}_{5 / 2}$ spectra. The $\mathrm{Ru} 3 \mathrm{~d}_{5 / 2}$ and $\mathrm{O} 1 \mathrm{~s}$ spectra undergo negligible lineshape changes in the temperature range $420-500 \mathrm{~K}$, despite the continuous increase of the $\mathrm{CO}_{2}$ yield. The deconvoluted $\mathrm{Ru}$ $3 \mathrm{~d}_{5 / 2}$ spectra have a dominant $\mathrm{Ru}(\mathrm{II})-\mathrm{O}_{\text {sub }}$ component at 0.5 $\mathrm{eV}$ and a rather weak $\mathrm{Ru}(\mathrm{I})-2 \mathrm{O}_{\mathrm{ad}} \mathrm{O}_{\text {sub }}$ component at $0.8 \mathrm{eV}$. This means that under the actual operational conditions the catalyst contains a significant amount of subsurface oxygen, whereas the $\mathrm{O}$ species on the surface are effectively consumed by the on-going reaction. The fast dynamics at the surface is confirmed by the practical absence of COrelated feature in the $\mathrm{O} 1 \mathrm{~s}$ spectra, indicating a short lifetime of the $\mathrm{CO}$ species on the surface before being reactedoff.

Since the $\mathrm{CO}_{2}$ formation reaction cannot disturb significantly the surface composition, the observed tempera- ture dependence of the reaction rate is most likely related to further accumulation of oxygen, facilitated at higher temperature. This accounts for the slow gradual increase of the $\mathrm{O} 1 \mathrm{~s}$ intensity below $500 \mathrm{~K}$, as illustrated in Fig. 4(b). In this context we note that the lattice stress induced by incorporation of $\mathrm{O}$ changes locally both the geometric and electronic structure of the top $\mathrm{Ru}$ layer [18,32], thereby affecting the $\mathrm{Ru}-\mathrm{O}$ and $\mathrm{Ru}-\mathrm{CO}$ adsorption bond and/or modifying the adsorbate bonding configurations. As a result the barrier to achieve the transition CO---O state may be reduced, increasing the surface activity and the $\mathrm{CO}_{2}$ yield.

A natural consequence of the progressive incorporation of oxygen with further increasing the reaction temperature is the nucleation and growth of stoichiometric $\mathrm{RuO}_{2}$. Indeed, the $\mathrm{Ru} 3 \mathrm{~d}_{5 / 2}$ spectra in Fig. 5(b) undergo significant changes above $500 \mathrm{~K}$, due to formation of $\mathrm{RuO}_{2}$ until a 'steady-state' composition is reached and maintained in the 550-600 $\mathrm{K}$ range. A weak $\mathrm{Ru}_{\text {bulk }}$ component can still be distinguished in the $\mathrm{Ru} 3 \mathrm{~d}_{5 / 2}$ spectrum of this 'steady-state', compared to much thicker $\mathrm{RuO}_{2}$ films grown in pure $\mathrm{O}_{2}$ ambient (see Fig. 3(a)). This indicates that the $\mathrm{RuO}_{2}$ growth during $\mathrm{CO}$ oxidation is slower, reflecting the kinetic limitations imposed by the presence of $\mathrm{CO}$. Considering our XPS microscopy findings [13] the hindered oxide growth should result in a patchy structure consisting of $\mathrm{RuO}_{2}$ islands and $\mathrm{Ru}_{\mathrm{x}} \mathrm{O}_{\mathrm{y}}$ areas, the latter accounting for the presence of the $\mathrm{Ru}_{\text {bulk }}$ component. A typical morphology of such surface is illustrated by the $\mathrm{Ru} 3 \mathrm{~d}_{5 / 2}$ image in the $\mathrm{O} 1 \mathrm{~s}$ panel in Fig. 5(a). The $\mathrm{RuO}_{2}$ islands appear dark (blue), because the $\mathrm{RuO}_{2}$ phase contains less $\mathrm{Ru}$ atoms per unit volume than the adsorption and O-rich intermediate states (green) and also being thicker it screens more effectively the emission from the metallic Ru below. Similar coexistence of the two phases was observed in very wide temperature $(600-775 \mathrm{~K})$ and exposure range $[13,21]$. Since the $\mathrm{Ru}_{\mathrm{x}} \mathrm{O}_{\mathrm{y}}$ component appears close to the cus- $\mathrm{Ru}$ component of the $\mathrm{RuO}_{2}(110)$ surface (see Table I), and it is speculative to fit the $\mathrm{Ru} 3 \mathrm{~d}_{5 / 2}$ spectra using three components with unknown weight we allowed a broadening of the dominant oxide component at $\sim 0.6 \mathrm{eV}$ to account for all contributions. The coexistence of the both oxidation states is confirmed by the corresponding $\mathrm{O} 1 \mathrm{~s}$ spectrum, which contains the 'surface oxide' and $\mathrm{RuO}_{2}$ components. Judging from the relative weight of the 'surface oxide' $\mathrm{O} 1 \mathrm{~s}$ component, about $80 \%$ of the surface should be covered with $\mathrm{RuO}_{2}$ islands at $590 \mathrm{~K}$. Note that the $\mathrm{RuO}_{2}$ bridge-O component at $528.7 \mathrm{eV}$ is very weak, probably due to its continuous consumption during the reaction, in accordance with the mechanism suggested in ref. 7,9 . The reaction rate can be reverted back and forth by decreasing-increasing the temperature in the range 550-600 K, which does not affect visibly the catalyst surface composition.

The most striking result is that the growth of the $\mathrm{RuO}_{2}$ phase above $500 \mathrm{~K}$ does not affect the monotonous increase of the $\mathrm{CO}_{2}$ yield (Fig. 4(a)). This suggests that the nucleation and growth of a stoichiometric oxide phase barely affects the reaction barrier. The plot of the $\mathrm{CO}_{2}$ yield 
vs $\mathrm{O}$ content in Fig. 4(c) is the best illustration that the high catalytic activity of the $\mathrm{Ru}$ catalyst is not exceptionally correlated to the formation of $\mathrm{RuO}_{2}$ with a well defined surface structure. It clearly shows that the 'surface oxide' formed via progressive incorporation of oxygen already exhibits high catalytic activity and there is no significant increase with the formation of stoichiometric $\mathrm{RuO}_{2}$. Here, it should be noted that since the formation of $\mathrm{RuO}_{2}$ occurs above $500 \mathrm{~K}$, when comparing the catalytic activity of the 'surface oxide' and $\mathrm{RuO}_{2}$ the positive temperature effect on the reaction rate should be taken into account as well.

The evidenced coexistence of 'surface oxide' and $\mathrm{RuO}_{2}$ states does not allow obtaining unambiguous results correlating the $\mathrm{CO}_{2}$ yield to a single phase by running the reaction at a constant temperature above $500 \mathrm{~K}$, when the nucleation and growth of the $\mathrm{RuO}_{2}$ takes place. However, the catalytic activity of the 'surface oxide' was confirmed by recent experiments performed using the stoichiometric $\mathrm{CO}: \mathrm{O}_{2}$ partial pressure ratio of 2 , instead of 1 , keeping the same total pressure of 0.1 mbar. We increased the temperature from 400 to $600 \mathrm{~K}$ in steps of 20-25 degrees, waiting at each temperature until the $\mathrm{CO}_{2}$ signal reaches a constant value. In this case the higher $\mathrm{CO}: \mathrm{O}_{2}$ gas pressure ratio hindered the formation of the $\mathrm{RuO}_{2}$ state. It was evidenced by the evolution of the $\mathrm{Ru} 3 \mathrm{~d}$ and $\mathrm{O} 1$ s spectra, which was terminated at the formation of 'surface oxide'. The $\mathrm{CO}_{2}$ yield grew steadily showing stable activity at constant temperature until levelling off at around $500 \mathrm{~K}$ and declining slowly above $550 \mathrm{~K}$. This result is qualitative agreement with the results with powdered Ru catalyst which demonstrate that an ultra-thin oxide layer covering the metallic $\mathrm{Ru}$ core is the active state in $\mathrm{CO}$ oxidation at temperatures below $500 \mathrm{~K}$ [33].

\section{Concluding remarks}

The in-situ capability of high-pressure photoelectron spectroscopy has provided real-time information about the evolution of chemical state of $\mathrm{Ru}(0001)$ catalyst during $\mathrm{CO}$ oxidation with increasing reaction temperature. The results confirm that the metallic state of $\mathrm{Ru}$ is inactive. The most important finding is that the $\mathrm{CO}_{2}$ production is not phase selective, i.e. there is no distinct difference between the catalytic activity of the stochiometric $\mathrm{RuO}_{2}(110)$ and a few layers thick not well-ordered 'surface oxide'.

According to the DFT predictions the higher catalytic activity of an oxide surface, compared to the corresponding metal surface, is not only due to the weaker $\mathrm{CO}$ and $\mathrm{O}$ bonding on the oxide; an important and in some cases even decisive role is the reorganisation required to achieve the configuration of the transition state [16]. In the frame of this concept the activation role of the subsurface oxygen should be ascribed to the induced deformation of the lattice, which affects the $\mathrm{O}$ and $\mathrm{CO}$ adsorption configurations. The growth of stoichiometric $\mathrm{RuO}_{2}$ does not change substantially the reaction barrier. This result is not surprising, because, as noted above, the activity is determined by the $\mathrm{O}$ and $\mathrm{CO}$ bonding configurations on the catalyst surface. Apparently, the amorphous surface oxide formed below $500 \mathrm{~K}$ has attained a favourable structure with activity comparable to that exhibited by the well-defined $\mathrm{RuO}_{2}$ phase formed at higher temperatures.

In excess of $\mathrm{CO}$ the limited amount of subsurface oxygen is energetically driven to segregate to the surface and the amorphous 'surface oxide' can easily lose the incorporated oxygen and convert into an inactive adsorption phase. However, the $\mathrm{RuO}_{2}$ also is unstable in excess of $\mathrm{CO}$ and similarly to the 'surface oxide' can be reduced into an inactive adsorption phase but it is not necessary to reoxidise back the reduced catalyst to the initial stoichiometric $\mathrm{RuO}_{2}$ in order to regain catalytic activity.

The surface phase diagram of the $\mathrm{RuO}_{2}(110)$ surface, reported in ref. 6 , considers that the catalytically active region under realistic dynamic reaction conditions can often lie at the boundary between two phases. The present study provides experimental evidence that the highest $\mathrm{CO}$ oxidation rate is monitored in the temperature range $500-$ $600 \mathrm{~K}$, when two Ru oxidation states coexist.

The results in this work apply well to real Ru catalyst systems, which are nano-particles forming amorphous oxide with not well-defined stoichiometry [34,35]. Such 'oxidized' states of the $\mathrm{Ru}$ nanoparticles, often described as $\mathrm{Ru}_{\mathrm{x}} \mathrm{O}_{\mathrm{y}}$, are comparable to the 'surface oxide' with subsurface oxygen rather than with the well-structured $\mathrm{RuO}_{2}(110)$ surface. We confirm in this study that the $\mathrm{RuO}_{2}$ formed at temperatures above $500 \mathrm{~K}$ is also active, but represents a limiting case of a well-ordered model structure. The longrange ordering of the $\mathrm{RuO}_{2}(110)$ surface is not prerequisite for catalytic function but was instrument to unravel and theoretically understand mechanisms of $\mathrm{CO}$ oxidation at the atomic level. As noted above, very recent study of the $\mathrm{CO}$ oxidation on polycrystalline powdered $\mathrm{Ru}$ catalyst in the temperature range $363-453 \mathrm{~K}$ showed that under dynamic catalytic conditions the active state are the ultra-thin $\mathrm{Ru}$ oxide films, whereas fully oxidized $\mathrm{RuO}_{2}$ particles, formed at higher temperature, exhibit lower activity [33]. This deactivation is tentatively attributed to roughening and formation of inactive $\mathrm{RuO}_{2}$ facets.

In general, the long-range ordered oxide structures available in macroscopic systems can not be the ones working under conditions of high chemical potential and enabled structural dynamics ("real world"). However, they are excellent model systems for fundamental experimental and theoretical studies of catalytic reactions. They help identifying the general reactivity trend on metallic and O-rich states of catalysts used in redox processes.

\section{Acknowledgements}

The authors are indebted to Dr. W. Ranke for the critical reading of the manuscript and the illuminating discussions. M. Kiskinova thanks $\mathrm{AvH}$ foundation for the Award to pursue research in FHI-Berlin in 2004-2005. P. Dudin acknowledges the financial support under Contract 
No. NMP3-CT-2003-505670 (NANO2). The BESSY staff is acknowledged for their continuous support to perform the present measurement.

\section{References}

[1] A. Böttcher, H. Niehus, S. Schwegmann, H. Over, G. Ertl, G. J. Phys. Chem. B 101 (1997) 11185.

[2] A. Böttcher, H. Niehus, J. Chem. Phys. 110 (1999) 3186; Phys. Rev. B 60 (1999)14396.

[3] H. Over, Y.D. Kim, A.P. Seitsonen, E. Lundgren, M. Schmid, P. Varga, A. Morgante, G. Ertl, Science 287 (2000) 1474.

[4] H. Over, A.P. Seitsonen, E. Lundgren, M. Wiklund, J.N. Andersen, Chem. Phys. Lett. 342 (2001) 467.

[5] Z.-P Liu, P. Hu, A. Alavi, J. Chem. Phys. 114 (2001) 5956.

[6] K. Reuter, M. Scheffler, Phys. Rev. Lett. 90 (2003) 46103; Phys. Rev. B 60 (2003) 45407.

[7] J. Wang, V.Y. Fan, K. Jacobi, G. Ertl, J. Phys. Chem. B 106 (2002) 3422.

[8] S. H. Kim, J. Wintterlin, J. Chem. Phys. B 108 (2004) 14565.

[9] K. Reuter, D. Frenken, M. Scheffler, Phys. Rev. Lett. 93 (2004) 116105.

[10] H. Over, M. Muhler, Prog. Surf. Sci. 72 (2003) 3 and references therein.

[11] H. Over, M. Knapp, E. Lundgren, A.P. Seitsonen, M. Schmid, P. Varga, ChemPhysChem 5 (2004) 167 and references therein.

[12] Y.D.Kim, H. Over, G. Krabbes, G. Ertl, Top. Catal. 14 (2001) 95.

[13] A. Böttcher, U. Starke, H. Conrad, R. Blume, L. Gregoriatti, B. Kaulich, A. Barinov, M. Kiskinova, J. Chem. Phys. 117 (2002) 8104.

[14] R. Blume, H. Niehus, H. Conrad, A. Böttcher, J. Phys. Chem. 108 (2004) 14332.

[15] A. Böttcher, B. Krenzer, H. Conrad, H. Niehus, Surf. Sci. 504 (2002) 42.

[16] X.-Q. Gong, Z.-P. Liu, R. Raval, P. Hu, J. Amer. Chem. Soc. 126 (2004) 8.

[17] One monolayer equals the number of Ru atoms on the (0001) surface. We use in further as an unit to express the total $\mathrm{O}$ load.

[18] M. Todorova, W.X. Li, M.V. Ganduglia-Pirovano, C. Stampfl, K. Reuter, M. Scheffler, Phys. Rev. Lett. 89 (2002) 96103.
[19] K. Reuter, C. Stampfl, M.V. Ganduglia-Pirovano, M. Scheffler, Chem. Phys. Lett. 352 (2002) 311.

[20] [P. Quinn, D. Brown, D.P. Woodruff, T.C.Q. Noakes, P. Bailey, Surf. Sci. 491 (2001) 208.

[21] R. Blume, H. Niehus, H. Conrad, A. Böttcher, L. Aballe, L. Gregoriatti, A. Barinov, M. Kiskinova, J. Phys. Chem. B 109 (2005) 14052.

[22] H. Over, A.P. Seitsonen, Science 297 (2002) 2003.

[23] H. Bluhm, M. Hävecker, A. Knop-Gericke, E. Kleimenov, R. Schlögl, D. Teschner, V.I. Bukhtiyarov, D.F. Ogletree, M. Salmeron, J. Phys. Chem. B. 108 (2004) 14340.

[24] D.F. Ogletree, H. Bluhm, C. Lebedev, C.S. Fadley, Z. Hussain, M. Salmeron, Rev. Sci. Instrum. 73 (2002) 3872.

[25] S. Lizzit, A. Baraldi, A. Groso, K. Reuter, M.V. GandugliaPirovano, C. Stampfl, M. Scheffler, M. Stichler, C. Keller, W. Würth, D. Menzel, Phys. Rev. B 63 (2001) 205419.

[26] M.P. Seah, Surf. Interface Anal. 9 (1986) 85

[27] H. Over, A.P. Seitsonen, E. Lundgren, M. Smedh, J.N. Anderesen, Surf. Sci. 504 (2002) L196.

[28] A. Schiffer, P. Jacob, D. Menzel, Surf. Sci. 389 (1997) 116.

[29] W.X. Li, C. Stampfl, M. Scheffler, Phys. Rev. B 67 (2003) 45408.

[30] C.H.F Peden, D.W. Goodman, J. Phys. Chem. 90 (1986) 1360.

[31] The Ru image is measured using the XPS scanning microscope station in the synchrotron laboratory in Trieste.

[32] M. Mavrikakis, B. Hammer, J.K. Norskov, Phys. Rev. Lett. 81 (1998) 2819.

[33] V. Narkhede, J. Assmann, M. Muhler, Z. Phys. Chem. 219 (2005) 979.

[34] W. Vogel, N. Alonso-Vante, J. Cat., 232 (2005) 395.

[35] B.-Z. Zhan, M.A. White, T.-K. Sham, J.A. Pincock, R. J. Doucet, K.V. Ramana Rao, K. N. Robertson, T.S. Cameron, J. Amer. Chem. Soc. 125 (2003) 2195. 